Maternal depression and trajectories of child internalising and externalising problems: The roles of child decision making and working memory

Eirini Flouri, Alexandra Ruddy \& Emily Midouhas

Department of Psychology and Human Development, UCL Institute of Education, University College London, UK

Correspondence and requests for reprints: Eirini Flouri, Department of Psychology and Human Development, UCL Institute of Education, University College London, 25 Woburn Square, London WC1H 0AA, UK. Tel: 0207612 6279; Fax: 0207612 6304; E-mail: e.flouri@ucl.ac.uk

Word count 4638 
Maternal depression and trajectories of child internalising and externalising problems: The roles of child decision making and working memory

\begin{abstract}
Background. Maternal depression may affect the emotional/behavioural outcomes of children with normal neurocognitive functioning less severely than it does those without. To guide prevention and intervention efforts, research must specify which aspects of a child's cognitive functioning both moderate the effect of maternal depression and are amenable to change. Working memory and decision making may be amenable to change and are so far unexplored as moderators of this effect. Methods. Our sample was 17,160 Millennium Cohort Study children. We analysed trajectories of externalising (conduct and hyperactivity) and internalising (emotional and peer) problems, measured (with the SDQ) at ages 3, 5, 7 and 11 years, using growth curve models. We characterised maternal depression, also time-varying at these ages, by a high score on the K6. Working memory was measured with the CANTAB Spatial Working Memory Task, and decision making (risk taking and quality of decision making) with the Cambridge Gambling Task, both at age 11. Results. Maternal depression predicted both the level and the growth of problems. Risk taking and poor-quality decision making were related positively to externalising and nonsignificantly to internalising problems. Poor working memory was related to both problem types. Neither decision making nor working memory explained the effect of maternal depression on child internalising/externalising problems. Importantly, risk taking amplified the effect of maternal depression on internalising problems, and poor working memory that on internalising and conduct problems. Conclusions. Impaired decision making and working memory in children amplify the adverse effect of maternal depression on, particularly, internalising problems.
\end{abstract}

Keywords: decision making, emotional and behavioural problems, maternal depression, MCS, working memory 


\section{Maternal depression and trajectories of child internalising and externalising problems: The roles of child decision making and working memory}

Maternal depression is a powerful risk factor of emotional (internalising) and behavioural (externalising) problems in children (Goodman et al. 2011). Nonetheless, some children are more resistant to its effects, while others are particularly vulnerable (Beardslee et al. 2011). One factor associated with such emotional/behavioural resilience or vulnerability is the child's neurocognitive functioning, especially as approximated by IQ (Lewandowski et al. 2014; Pargas et al. 2010). The reasons why child's high cognitive functioning buffers against (or low cognitive functioning amplifies) the adverse impact of mother's depression are not clear. A plausible explanation is that high cognitive functioning protects children from the effect of maternal negative cognitions, associated with depression. For instance, a child with high cognitive functioning may actively engage in a form of source monitoring (Riglin et al. 2015) as a coping strategy against maternal depression, effectively filtering out negative cognitive messages received from the mother.

To guide prevention and intervention efforts, research must specify which aspects of child cognitive functioning both moderate the effect of maternal depression on child emotional/behavioural problems and are amenable to change. Working memory and decision making are major (and distinct from one another) theoretical constructs in cognitive psychology and have been shown to improve, respectively, with training (Klingberg et al. 2002) and in favourable (such as low-stress) contexts (Galván \& McGlennen 2012). Importantly, they are so far unexplored as moderators of the effect of maternal depression on child internalising and externalising problems, despite evidence that they can moderate the effect of other risk factors on behaviours closely related to internalising and externalising problems in children and adolescents, such as alcohol or drug use (Gorka et al. 2015; Grenard et al. 2008). However, both working memory and decision making in children can also be influenced by maternal depression (Klimes-Dougan et al. 2006; Morgan et al. 2014). It is therefore important to investigate their roles in both mediating (explaining) 
and moderating the effect of maternal depression on child internalising and externalising problems. We undertook this study to do this.

\section{Working memory and decision making}

Working memory capacity, typically assessed with delay tasks, is the ability to retain and manipulate information during a short period of time. Working memory is one of the most influential theoretical constructs in cognitive psychology due to its links with developmental cognitive disorders but also a wide variety of real-world skills (Cohen \& Conway 2008). Working memory underlies complex reasoning and is still regarded as a somewhat fixed individual trait, despite some (contested) evidence that it can also improve with training (Melby-Lervåg \& Hulme 2013). Impaired decision making refers to decision-making deficits, usually measured with gambling tasks, seen in individuals with deficient ventromedial prefrontal cortex function (Fellows \& Farah 2005). The ventromedial prefrontal cortex is activated when individuals make choices that they are uncertain about (e.g., when guessing) and that involve rewards and punishments based on those choices.

Research in developmental cognitive science has shown improvements in skills related to functioning in the dorsolateral region of the prefrontal cortex - such as those involving working memory, spatial working memory and planning - during childhood, when abilities linked to functioning in the ventromedial prefrontal cortex also improve. Nonetheless, there are not significant correlations between performance on working memory tasks and that on decisionmaking tasks, suggesting that the maturation of the ventromedial prefrontal cortex may be a developmentally distinct process from the maturation of other regions of the frontal lobe (Steinberg 2005 for a review). It appears therefore that working memory and decision making depend, in part, on separate anatomical substrates (Bechara et al. 1998), and thus that cognitive functions related to working memory are distinct from those related to decision making. However, this non-dependence 
may be more nuanced than initially thought. For example, studies in clinical samples sometimes show inter-relationships, perhaps reflecting the presence of multiple deficits in functioning in clinical populations (Toplak et al. 2010). Intriguingly, there is also evidence that the two may be asymmetrically dependent. While working memory is not dependent on the intactness of decision making (i.e., one can have normal working memory in the presence or absence of deficits in decision making), decision making seems to be influenced by the intactness or impairment of working memory (decision making is found to be worse in the presence of poor working memory) (Bechara et al. 1998).

\section{The roles of working memory and decision making in child internalising and externalising problems}

Both poor working memory and poor decision making have been linked to internalising and externalising problems in children. For example, deficits in executive functioning, including working memory, play a significant role in ADHD (Castellanos \& Tannock 2002). Importantly, in both ADHD and non-ADHD children, impaired working memory is related to ineffective social functioning. Because of difficulties in holding and processing information, children with poor working memory tend to respond more impulsively and without careful forethought in social situations, for example by using physical aggression rather than other more socially skilled means of expressing themselves, in turn inviting peer rejection (McQuade et al. 2013). Poor working memory is also related to depression and internalising symptoms in youth (Baune et al. 2014). One reason may be that working memory deficits lead to rumination, which is strongly related to depression. Youth (and adults) prone to ruminate tend to perseverate on recurring thoughts that revolve around a particular theme and have difficulty flexibly switching to a new train of thought; such perseveration may reflect difficulties in working memory (Joormann et al. 2011). Decision-making deficits are also associated with adverse behavioural and health outcomes, but with evidence for specificity in this association by both type of deficit and class of outcome. In general, poor decision making reflecting 
reward hyposensitivity and diminished reward seeking is related to internalising problems, such as depression (Rawal et al. 2013). Poor decision making reflected in enhanced responses to rewarding outcomes and deficits in the activity of motivational circuitry during anticipation of rewards is generally related to externalising behaviours (Ernst et al. 2003).

\section{The present study}

We used data from the UK's Millennium Cohort Study (MCS), collected when children were 3, 5, 7 and 11 years old. First, we assessed the effect of maternal depression on children's trajectories of internalising and externalising problems. Then we examined whether spatial working memory (the only type of working memory measured in MCS so far) and decision making (quality of decision making and risk taking) moderate this effect. Because maternal depression has been related to both working memory deficits and impaired decision making in children, in turn associated with problem behaviour, we also investigated the roles of spatial working memory and decision making in explaining the association between maternal depression and child internalising and externalising problems. In addition, we estimated the effect of their interaction to account for their asymmetrical relationship. We controlled for confounding by adjusting for factors associated with both maternal depression and child internalising and externalising problems, including poverty, maternal education and family structure (Kiernan \& Mensah 2009). Where possible, our variables were time-varying for ages 3-11 years.

\section{Method}

\section{Participants and procedure}

MCS is a population-based longitudinal birth cohort study of children born in the UK over 12 months from 1 September 2000. Children were around 9 months old at Sweep 1, and around 3, 5, 7 and 11 years old at Sweep 2, 3, 4 and 5, respectively. MCS was designed to over-represent families 
living in areas of high child poverty, areas with high proportions of ethnic minority populations across England, and the three smaller UK countries. Parent-reported data were collected through interviews and self-completion questionnaires. Ethical approval was gained from NHS Multi-Centre Ethics Committees, and parents gave informed consent before interviews took place. At Sweep 1, 18,522 families participated in MCS. The numbers of productive families at Sweeps $2,3,4$ and 5 were $15,590,15,246,13,857$ and 13,287 respectively. In all, 19,244 families participated in MCS. The analytic sample $(n=17,160)$ consisted of children (singletons and the first-born child of the families with twins or triplets in the cohort) with valid data on internalising and externalising problems in at least one of Sweeps 2-5.

\section{Measures}

Internalising and externalising problems were measured with the four difficulties scales of the parent-reported Strengths and Difficulties Questionnaire (SDQ; Goodman 1997) in Sweeps 2-5. The SDQ was completed by the main caregivers at Sweeps 2-4 and both the main caregivers and their partners at Sweep 5. In this study, the partner-reported SDQ scales were used when the main caregiver's SDQ data were missing. The four scales (emotional symptoms, peer problems, hyperactivity and conduct problems) have five items each. Each item is rated on a 3-point scale from not true (0) to certainly true (2). In our sample, internal consistency was good for hyperactivity ( $\alpha=$ .71 to .79 across sweeps), acceptable for conduct and emotional problems ( $\alpha=.56$ to .68 and $\alpha=.51$ to .71 , respectively, across sweeps) and poor for peer problems ( $\alpha=.47$ to .64 across sweeps).

Maternal depression was measured at Sweeps 2-5 with a high score (13+) on the K6 (Kessler et al. 2003; $\alpha=.87$ to .90 across sweeps).

Spatial working memory was measured with the Cambridge Neuropsychological Test Automated Battery (CANTAB) Spatial Working Memory Task (Robbins et al. 1994) at Sweep 5. In this test, participants must search for blue tokens by touching the coloured boxes to open them. The 
task becomes more difficult as the number of boxes increases. The critical instruction is that the participant must not return to a box where a token has previously been found. The test begins with a number of coloured squares (boxes) being shown on the screen. The aim of the task is that, by touching the boxes and using a process of elimination, the participant should find one blue 'token' in each of a number of boxes and use them to fill up an empty column on the right-hand side of the screen. The number of boxes is gradually increased, until it is necessary to search a total of eight boxes. The colour and position of the boxes used are changed from trial to trial to discourage the use of stereotyped search strategies. The outcome measure used in this study was number of total errors, that is, the number of times a participant touches a box that is certain not to contain a token. It is therefore the sum of errors made within searches (within errors, i.e., whether the participant revisited a box known to be empty) and the number of errors made between searches (between errors, i.e., whether the participant revisited a box where a blue token had already been found). High scores on this working memory variable (total errors) therefore indicate poor spatial working memory.

Decision making was measured with the Cambridge Gambling Task (Rogers et al. 1999) at Sweep 5. On each trial, the participant is presented with a row of ten boxes across the top of the screen, some of which are red and some of which are blue. At the bottom of the screen are rectangles containing the words 'Red' and 'Blue'. The participant must guess whether a yellow token is hidden in a red or a blue box. In the gambling stages, participants start with a number of points, displayed on the screen, and can select a proportion of these points, displayed in either rising or falling order, in a second box on the screen, to gamble on their confidence in this judgement. A stake box on the screen displays the current amount of the bet. The participant must try to accumulate as many points as possible. A strength of the task is that all the information needed to make the decision and place the bet is presented visually on the screen and each trial is independent of the last. Thus, working memory and learning processes are minimised. The task produces several 
outcome measures, of which two were used in this study, risk taking and quality of decision making. Risk taking is the mean proportion of points bet on trials where the most likely outcome was chosen. Quality of decision making is the mean proportion of trials where the participant selects the correct colour outcome.

The child covariates were gender and ethnicity (white or not). The family covariates were maternal education (whether the mother had a university degree or not), family structure (two natural parents at home or not; measured at Sweeps 2-5) and family poverty. Family poverty was measured at Sweeps 2-5 with a composite measure of socio-economic disadvantage (Malmberg \& Flouri 2011). This was the mean of four dichotomous variables: overcrowding (more than 1.5 people per room excluding bathroom and kitchen), lack of home ownership, receipt of income support and income poverty (below the poverty line).

\section{Statistical analysis}

To examine the direct effect of maternal depression, and its mediation and moderation by child working memory and decision making, on child internalising and externalising problems at ages 3-11 years we fitted growth curve models (Snijders \& Bosker 1999). This approach allowed the estimation of individual problem trajectories by specifying an independent variable for time. In this study, the time variable was age in years, centred at age 7. Emotional, conduct and peer problems had a quadratic trajectory, on average, and hyperactivity a cubic, on average (described in Results). We had two random slopes - one for age and one for age $^{2}$ - to account for individual linear and nonlinear trajectories. We did not have enough timepoints of data to include a random effect for age ${ }^{3}$ for hyperactivity. Our models were two-level, with occasion (Level 1) nested within child (Level 2). This approach captures not only the individual differences between children's internalising and externalising problems at different ages but also the differences across time at different sweeps, as it takes into account the correlations between measurements at each occasion for each child. These 
models specify both fixed and random parameters. The fixed parameters are the intercept (the mean emotional, conduct, hyperactivity and peer problem scores at age 7) and the slope (the mean change in scores per year). Given the shape of the average trajectories, we also included fixed effects for age ${ }^{2}$ for conduct, emotional and peer problems, and a fixed effect for age ${ }^{3}$ for hyperactivity. The random parameters are between-occasion variance (variation between occasions for each child), between-child intercept variance (variation between children at age 7), betweenchild age slope variance (variation between children in linear change in scores annually), betweenchild age ${ }^{2}$ slope variance (variation between children in quadratic change in scores annually), covariance of the between-child intercept variance and the between-child age slope variance (the relationship between scores at age 7 and their annual linear change), covariance of the betweenchild intercept variance and the between-child age ${ }^{2}$ slope variance (the relationship between scores at age 7 and their annual quadratic change), and covariance of the between-child age slope variance and the between-child age ${ }^{2}$ slope variance (the relationship between the variances in linear and quadratic annual change in scores).

Models were estimated in MLwiN 2.32, a statistical package for multilevel modelling. The sequence of models fitted is shown in Table 1. Model 1 contains age and age ${ }^{2}$ entered as fixed and random effects. $\mathrm{Age}^{3}$ was also entered as a fixed effect in the models for hyperactivity. Models 2-7 were conditional and therefore the variances and covariances reflect residual variability, i.e., variability not accounted for by the considered covariates. As can be seen, the model sequence and approach we adopted allowed us to test the mediation and the moderation of the effect of maternal depression by working memory and decision making as well as the relationship between working memory and decision making. Models 4 and 5 are the key models. The MCS sampling design was accounted for in all conditional models by controlling for stratification.

(Table 1) 


\section{Results}

\section{Bias analysis and descriptive statistics}

As can be seen in Supplementary Tables 1-2, compared to children in the non-analytic sample, those in the analytic sample were more likely to be white, come from less socioeconomically disadvantaged families and show better performance on the working memory (but not the gambling) task. The mean scores of children's emotional, conduct and peer problems at the four sweeps showed U-shaped trajectories, whereas that for hyperactivity followed a cubic trend. The proportions of mothers scoring above cut-off on the K6 at Sweeps 2-5 were rather high, ranging from $3.4 \%$ to $6.4 \%$.

(Supplementary Tables 1-2)

\section{Bivariate associations}

As can be seen in Supplementary Table 3 which presents the contemporaneous correlations between the three mediator/moderator variables and some of the key study variables, poor performance on any of the three tasks was related positively to externalising problems, maternal depression and socio-economic disadvantage. Risk taking was not related to emotional symptoms, and male gender and non-white ethnicity were each associated with poorer working memory and more risk taking. However, all these correlations were weak ${ }^{1}$. The gambling and working memory tasks were also very weakly inter-related, at .09 (total errors and risk taking), .11 (quality of decision making and risk taking) and -.17 (total errors and quality of decision making).

\footnotetext{
${ }^{1}$ We also explored the correlations between spatial working memory and the cognitive ability measures at age 5 (the MCS data sweep with the most comprehensive measurement of cognitive ability in childhood). These were modest at -.19 (BAS Naming Vocabulary), -.19 (BAS Picture Similarities), -.31 (BAS Pattern Construction) and -.31 [general cognitive ability (the 'IQ' score derived from a factor analysis of the three BAS scores)]. There was a similar pattern of associations between these cognitive ability measures and the two gambling task measures, that is, the correlations for quality of decision making were, respectively, .10, .09, .13 and .15; for risk taking they were, respectively, $-.10,-.07,-.09$ and -.11 .
} 
(Supplementary Table 3)

\section{Growth curve models}

Model 1 (Supplementary Table 4), the unconditional model, showed that the within-child and between-child variance was larger in hyperactivity than in the other problems, suggesting that hyperactivity scores both varied more over time than the other types of problems and differed more between families. As expected, the between-child variances were larger than the between-occasion variances across all SDQ domains indicating that children differed more from each other in terms of SDQ scores than their scores did over time. The intraclass correlations (ICCs) for emotional problems were .58 and .42 (levels 2 and 1, respectively). For conduct problems, the ICCs were .56 and .44 (levels 2 and 1, respectively) and for hyperactivity they were .71 and .29, respectively. For peer problems, the ICCs at levels 2 and 1, respectively, were .57 and .43 . Model 2 showed that the family and child covariates were significant on all four problem types and that their addition decreased, as expected, the between-child variance in all four problem scores. Model 3 showed that maternal depression was significantly related to all four problems at central age as well as to the linear slope of both emotional and conduct problems and the quadratic slope of conduct problems. As can be seen in Models 4-5 (Table 2), poor working memory and poor decision making did not explain the effect of maternal depression on internalising and externalising problems. Poor working memory capacity was related to all four problem types, but both risk taking and quality of decision making were related (positively and negatively) to externalising problems only. There was not a significant interaction between risk taking and working memory in Model 4. However, working memory and quality of decision making interacted to predict both peer and emotional problems, such that there was an adverse effect of poor-quality decision-making on internalising problems in the presence of low working-memory capacity (Model 5). Models 6-7 estimated the effects of the interactions between working memory and maternal depression and between decision making and maternal depression. These models showed that working memory interacted with maternal depression to 
predict conduct, peer and emotional problems, such that working memory deficits exacerbated the adverse effect of maternal depression. There were also significant interactions between maternal depression and risk taking on both emotional and peer problems, such that risk taking amplified the adverse effect of maternal depression, but no interactions between maternal depression and quality of decision making on any problem type. In general, there were no interactions between maternal depression and either decision making or working memory on hyperactivity. Figures 1-3 illustrate some of these multiplicative effects.

(Supplementary Table 4, Table 2 and Figures 1-3)

\section{Discussion}

We carried out this study to explore, for the first time, the roles of child spatial working memory and child decision making in the longitudinal association between maternal depression and child internalising and externalising problems from preschool age to the end of primary school. In general, the effect of maternal depression on child externalising and internalising problems was robust to adjustment for confounding and was not explained by either poor working memory or poor decision making. Working memory deficits were related to both externalising and internalising problems but also amplified the adverse effect of maternal depression on both outcomes. Decisionmaking deficits, predictive of externalising problems only, were also related to such vulnerability but effects were specific to both type of outcome and type of decision-making impairment. Risk taking but not poor-quality decision making accentuated the adverse effect of maternal depression, and only on internalising problems. However, there was an adverse effect of poor-quality decisionmaking on internalising problems in the presence of poor working memory, in line with evidence for the asymmetrical relationship between working memory and decision making (Bechara et al. 1998).

Together, these findings suggest that whilst children with either poor working memory or depressed mothers are at risk of internalising and externalising problems, interventions to prevent or treat child internalising and externalising problems may be particularly effective if they target children with poor working memory in families with a history of maternal depression. Children with 
depressed mothers and cognitive impairments therefore may be particularly vulnerable to internalising and externalising disorders. They also suggest that while risk taking may not be a risk factor of internalising problems, it can accentuate the effect of maternal depression on these problems.

The independence found here between our moderator variable (risk taking) and our psychopathological outcome (internalising problems) is certainly not unusual. In line with much research on child emotional/behavioural resilience and vulnerability, protective and vulnerability factors can moderate the effect of a risk factor on a child psychopathological outcome even if they themselves are not related to either the risk factor or the child outcome (Rutter 2012). The weak association between maternal depression and child decision making however was unexpected. Research with late adolescents and young adults has shown that those with a family history of parental depression generally show diminished risk taking (Mannie et al. 2015). Several mechanisms have been proposed to explain this. For example, they may be hyposensitive to rewards (or oversensitive to loss) or they may have a lower overall assessment of the likelihood of a positive outcome, which lowers the potential utility of a risky choice. A reason for our different findings may be that we measured risk of depression rather than clinical depression in mothers. Another may be that we estimated the association between risk taking and risk of maternal depression in childhood. When the data from the adolescent sweeps of MCS become available, we will be able to test the second hypothesis.

Our findings with respect to the effect of maternal depression on child spatial working memory are also noteworthy. As discussed, we expected that child spatial working memory would both moderate and explain (mediate) the effect of maternal depression on child behavioural and emotional problems but we could not predict what it would do more of. There were certainly arguments for both positions. For example, maternal depression, as a well-recognised and powerful stressor in children (and thus a risk factor of child emotional/behavioural problems), would impair 
child spatial working memory (i.e., child spatial working memory would mediate the effect of maternal depression on child emotional/behavioural problems) because stress impairs the prefrontal cortex (Arnsten 2009), which subserves the highest-order cognitive abilities, including spatial working memory thus leading to behavioural and psychological difficulties. However, there is also evidence that high working-memory capacity can 'dampen' the effects of stressors (i.e., child spatial working memory would moderate the effect of maternal depression on child behavioural problems) (Brewin \& Smart 2005) because of the role of working memory in promoting selfregulation (Hofmann et al. 2012), a well-known protective 'buffer'. Our study showed that child poor spatial working memory accentuated but did not explain the effect of maternal depression on child behavioural and emotional problems.

Our study is not without limitations. As mentioned, we did not have clinical measures of depression to allow us to make direct comparisons with earlier studies of maternal depression effects on children. This, in turn, suggests that we cannot explain well any differences between our findings and others' (such as our null mediator effects). Furthermore, the low reliability of some of our measures (such as the peer problems scale) require that we treat some of our findings with caution. Another limitation, or at least an important point to consider, is that the effect sizes of the interaction terms capturing the multiplication of the effect of maternal depression by child cognitive functioning were rather weak. As can be seen in the figures which plot these interaction effects however, cognitive functioning differentiated substantially the problem trajectories of children of depressed mothers, suggesting that information about child cognitive functioning can help identify the most vulnerable children within the high-risk group of children in families with depressed mothers. Perhaps the most significant limitation is the lack of longitudinal assessments for the cognitive measures. In our sample, both spatial working memory and decision making were measured once, at age 11 years. The assumption we had to made in the models therefore was that both were time-invariant between ages 3 and 11 years. We acknowledge that the stability across our 
full study period may be a bold assumption but our pattern of findings did not change when we replicated our analyses for ages 5-11 years (results available from the authors), a period of relative stability for both constructs. Spatial working memory shows stability rather than change across the primary school years (Gathercole et al. 2004; Pickering 2001) and while decision making can change markedly as children move into adolescence, performance on similar gambling tasks as the Cambridge Gambling Task shows few changes in middle childhood (Crone et al. 2004; Smith et al. 2012). Some evidence does suggest that pubertal status may moderate the relationship between age and performance on gambling tasks (Smith et al. 2013) but Flouri et al. (under review) showed, also using MCS and the Cambridge Gambling Task, that pubertal status did not predict decision making after correcting for some of the variables also adjusted for in this study, such as socioeconomic status and maternal depression.

These limitations however should not distract from the study's important unique strengths, including the large population-based longitudinal sample and the measurement of decision making by a gambling task that uniquely dissociates working memory from genuine risk-taking behaviour (Manes et al. 2002). Our study showed that mother's depression does not cause child's internalising and externalising problems by impairing his/her cognitive functioning, at least as measured by spatial working memory capacity and decision making and across the developmental stage we considered. Rather, poor spatial working memory and poor decision making exacerbated the adverse effect of maternal depression. These findings have implications for both theory and practice. They are important for theoretical models of maternal depression effects on children but they can also be used to inform efforts to reduce or prevent child emotional and behavioural problems by specifying with precision a high-risk population who should be targeted in these efforts. 
Table 1.

Model Summary

\begin{tabular}{|c|c|}
\hline Models & Specification \\
\hline Model 1 & Age (centred at 7) in years $+\mathrm{Age}^{2}+\mathrm{Age}^{3 \mathrm{a}}$ \\
\hline Model 2 & Model $1+$ Stratum variables ${ }^{b}+$ Family $^{c}$ covariates + Child $^{d}$ covariates \\
\hline Model 3 & $\begin{array}{l}\text { Model } 2+\text { Maternal depression + Maternal depression } x \text { age + Maternal } \\
\text { depression } x \text { age }^{2}+\text { Maternal depression } x \text { age }^{3 e}\end{array}$ \\
\hline Model 4 & $\begin{array}{l}\text { Model } 3+\text { Poor spatial working memory }(S W M)+\text { Risk taking + Poor SWM } x \text { risk } \\
\text { taking }\end{array}$ \\
\hline Model 5 & $\begin{array}{l}\text { Model } 3+\text { Poor SWM + Quality of decision making + Poor SWM } x \text { quality of } \\
\text { decision making }\end{array}$ \\
\hline Model 6 & Model 4 + Maternal depression $\times$ poor SWM + Maternal depression $\times$ risk taking \\
\hline Model 7 & $\begin{array}{l}\text { Model } 5+\text { Maternal depression } \mathrm{x} \text { poor SWM + Maternal depression } \mathrm{x} \text { quality of } \\
\text { decision making }\end{array}$ \\
\hline
\end{tabular}

a,e For hyperactivity only.

${ }^{\mathrm{b}}$ The MCS stratum variables are England-Advantaged (reference group), England-Disadvantaged,

England-Ethnic, Wales-Advantaged, Wales-Disadvantaged, Scotland-Advantaged, Scotland-

Disadvantaged, Northern Ireland-Advantaged and Northern Ireland-Disadvantaged.

${ }^{c}$ Poverty, maternal education and family structure.

${ }^{\mathrm{d}}$ Gender and ethnicity. 
Table 2.

Fixed Effects Estimates and Variance Covariance Estimates of Problem Trajectories (Models 4 and 5)

\begin{tabular}{|c|c|c|c|c|c|c|c|c|}
\hline & \multicolumn{2}{|c|}{ Emotional symptoms } & \multicolumn{2}{|c|}{ Conduct problems } & \multicolumn{2}{|c|}{ Hyperactivity } & \multicolumn{2}{|c|}{ Peer problems } \\
\hline & Model 4 & Model 5 & Model 4 & Model 5 & Model 4 & Model 5 & Model 4 & Model 5 \\
\hline Age & $\begin{array}{c}0.053(0.00 \\
3)^{* * *}\end{array}$ & $\begin{array}{c}0.054(0.00 \\
3)^{* * *}\end{array}$ & $\begin{array}{c}- \\
0.222(0.003)^{* *} \\
*\end{array}$ & $\begin{array}{c}0.222(0.003 \\
)^{* * *}\end{array}$ & $\begin{array}{c}0.038(0.010) \\
* * *\end{array}$ & $\begin{array}{c}0.037(0.01 \\
0)^{* * *}\end{array}$ & $\begin{array}{c}- \\
0.042(0.003 \\
)^{* * *}\end{array}$ & $\begin{array}{c}- \\
0.042(0.003)^{*} \\
* *\end{array}$ \\
\hline $\mathrm{Age}^{2}$ & $\begin{array}{c}0.005(0.00 \\
1)^{* * *}\end{array}$ & $\begin{array}{c}0.005(0.00 \\
1)^{* * *}\end{array}$ & $\begin{array}{c}0.049(0.001)^{* *} \\
*\end{array}$ & $\begin{array}{c}0.049(0.001 \\
)^{* * *}\end{array}$ & $\begin{array}{c}0.029(0.001) \\
* * *\end{array}$ & $\begin{array}{c}0.029(0.00 \\
1)^{* * *}\end{array}$ & $\begin{array}{c}0.017(0.001 \\
)^{* * *}\end{array}$ & $\begin{array}{c}0.017(0.001)^{*} \\
* *\end{array}$ \\
\hline $\begin{array}{l}\text { Stratum (ref. = } \\
\text { England-adv.) }\end{array}$ & & & & & & & & \\
\hline England-disadv. & $\begin{array}{c}0.131(0.03 \\
1)^{* * *}\end{array}$ & $\begin{array}{c}0.132(0.03 \\
1) * * *\end{array}$ & $\begin{array}{c}0.209(0.030) \\
* * *\end{array}$ & $\begin{array}{c}0.207(0.030 \\
)^{* * *}\end{array}$ & $\begin{array}{c}0.207(0.047) \\
* * *\end{array}$ & $\begin{array}{c}0.203(0.04 \\
7)^{* * *}\end{array}$ & $\begin{array}{c}0.205(0.028 \\
)^{* * *}\end{array}$ & $\begin{array}{c}0.206(0.028)^{*} \\
* *\end{array}$ \\
\hline Wales-disadv. & $\begin{array}{l}0.041(0.04 \\
1)\end{array}$ & $\begin{array}{l}0.040(0.04 \\
1)\end{array}$ & $0.093(0.040)^{*}$ & $\begin{array}{c}0.062(0.041 \\
)\end{array}$ & $0.106(0.062)$ & $\begin{array}{c}0.051(0.06 \\
2)\end{array}$ & $\begin{array}{c}0.111(0.038 \\
)^{* *}\end{array}$ & $\begin{array}{c}0.107(0.038)^{*} \\
*\end{array}$ \\
\hline Scotland-adv. & $\begin{array}{c}- \\
0.090(0.04 \\
9)\end{array}$ & $\begin{array}{c}- \\
0.093(0.04 \\
9)\end{array}$ & $-0.030(0.049)$ & $\begin{array}{c}- \\
0.054(0.049 \\
)\end{array}$ & $\begin{array}{c}- \\
0.170(0.075) \\
*\end{array}$ & $\begin{array}{c}- \\
0.214(0.07 \\
5)^{* *}\end{array}$ & $\begin{array}{c}- \\
0.052(0.045 \\
)\end{array}$ & $-0.059(0.046)$ \\
\hline $\begin{array}{l}\text { Scotland- } \\
\text { disadv. }\end{array}$ & $\begin{array}{c}- \\
0.043(0.05 \\
1) \\
\end{array}$ & $\begin{array}{c}- \\
0.046(0.05 \\
1) \\
\end{array}$ & $0.022(0.050)$ & $\begin{array}{c}- \\
0.003(0.051 \\
i \\
\end{array}$ & $0.022(0.077)$ & $\begin{array}{c}- \\
0.023(0.07 \\
8) \\
\end{array}$ & $\begin{array}{c}0.023(0.047 \\
)\end{array}$ & $0.018(0.047)$ \\
\hline $\begin{array}{l}\text { Northern } \\
\text { Ireland-adv. }\end{array}$ & $\begin{array}{c}- \\
0.011(0.05 \\
9)\end{array}$ & $\begin{array}{c}- \\
0.006(0.05 \\
9)\end{array}$ & $-0.136(0.058)^{*}$ & $\begin{array}{c}- \\
0.165(0.058 \\
)^{* *}\end{array}$ & $\begin{array}{c}- \\
0.226(0.090) \\
*\end{array}$ & $\begin{array}{c}0.270(0.09 \\
0)^{* *}\end{array}$ & $\begin{array}{c}- \\
0.058(0.054 \\
)\end{array}$ & $-0.055(0.054)$ \\
\hline
\end{tabular}




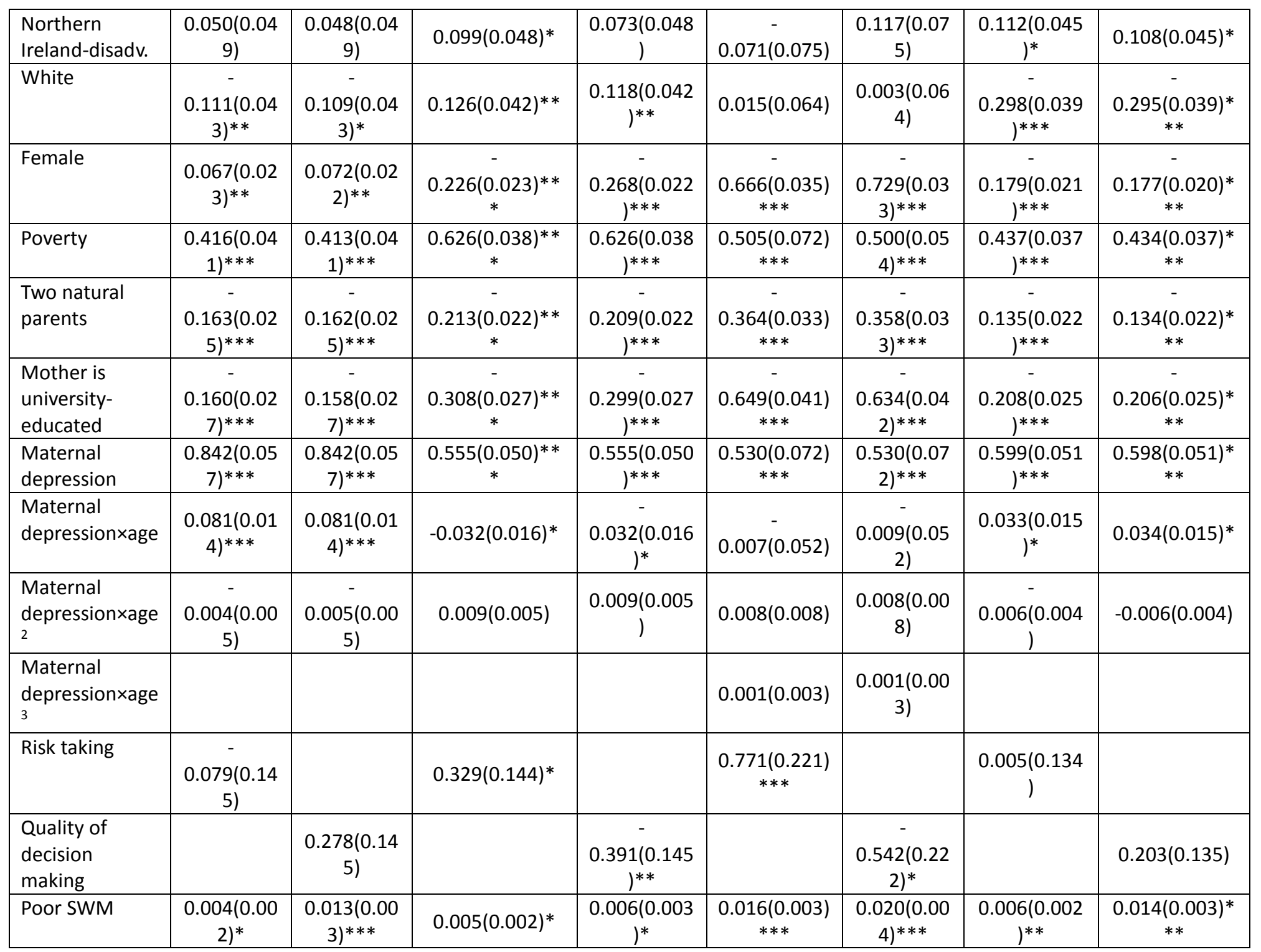




\begin{tabular}{|c|c|c|c|c|c|c|c|c|}
\hline $\begin{array}{l}\text { Risk } \\
\text { taking×poor } \\
\text { SWM }\end{array}$ & $\begin{array}{c}0.001(0.00 \\
4)\end{array}$ & & $0.004(0.003)$ & & $\begin{array}{c}- \\
0.002(0.005)\end{array}$ & & $\begin{array}{c}- \\
0.000(0.003 \\
)\end{array}$ & \\
\hline $\begin{array}{l}\text { Quality of } \\
\text { decision } \\
\text { making×poor } \\
\text { SWM }\end{array}$ & & $\begin{array}{c}- \\
0.011(0.00 \\
3)^{* * *}\end{array}$ & & $\begin{array}{c}0.001(0.003 \\
)\end{array}$ & & $\begin{array}{c}- \\
0.006(0.00 \\
5)\end{array}$ & & $\begin{array}{c}- \\
0.010(0.003)^{*} \\
* *\end{array}$ \\
\hline \multirow[t]{2}{*}{ Constant } & $\begin{array}{c}1.383(0.09 \\
7)^{* * *}\end{array}$ & $\begin{array}{c}1.113(0.13 \\
4)^{* * *} \\
\end{array}$ & $\begin{array}{c}0.924(0.095)^{* *} \\
* \\
\end{array}$ & $\begin{array}{c}1.451(0.132 \\
)^{* * *}\end{array}$ & $\begin{array}{c}2.865(0.146) \\
* * * \\
\end{array}$ & $\begin{array}{c}3.772(0.20 \\
3)^{* * *} \\
\end{array}$ & $\begin{array}{c}1.226(0.089 \\
)^{* * *}\end{array}$ & $\begin{array}{c}1.064(0.123)^{*} \\
* *\end{array}$ \\
\hline & \multicolumn{8}{|c|}{ Random effects } \\
\hline $\begin{array}{l}\text { Between-child } \\
\text { intercept } \\
\text { variance }\end{array}$ & $\begin{array}{c}1.472(0.03 \\
2)^{* * *}\end{array}$ & $\begin{array}{c}1.470(0.03 \\
2)^{* * *}\end{array}$ & $\begin{array}{c}1.066(0.024)^{* *} \\
*\end{array}$ & $\begin{array}{c}1.069(0.024 \\
)^{* * *}\end{array}$ & $\begin{array}{c}3.579(0.064) \\
* * *\end{array}$ & $\begin{array}{c}3.582(0.06 \\
4)^{* * *}\end{array}$ & $\begin{array}{c}1.083(0.024 \\
)^{* * *}\end{array}$ & $\begin{array}{c}1.081(0.024)^{*} \\
* *\end{array}$ \\
\hline $\begin{array}{l}\text { Between-child } \\
\text { slope variance } \\
\text { (age) }\end{array}$ & $\begin{array}{c}0.031(0.00 \\
1)^{* * *}\end{array}$ & $\begin{array}{c}0.031(0.00 \\
1)^{* * *}\end{array}$ & $\begin{array}{c}0.047(0.001)^{* *} \\
*\end{array}$ & $\begin{array}{c}0.047(0.001 \\
)^{* * *}\end{array}$ & $\begin{array}{c}0.063(0.002) \\
* * *\end{array}$ & $\begin{array}{c}0.063(0.00 \\
2)^{* * *}\end{array}$ & $\begin{array}{c}0.037(0.001 \\
)^{* * *}\end{array}$ & $\begin{array}{c}0.037(0.001)^{*} \\
* *\end{array}$ \\
\hline $\begin{array}{l}\text { Between-child } \\
\text { slope variance } \\
\left(\mathrm{age}^{2}\right)\end{array}$ & $\begin{array}{c}0.001(0.00 \\
0)\end{array}$ & $\begin{array}{c}0.001(0.00 \\
0)\end{array}$ & $0.002(0.000)^{*}$ & $\begin{array}{c}0.002(0.000 \\
)^{*}\end{array}$ & $\begin{array}{c}0.002(0.000) \\
*\end{array}$ & $\begin{array}{c}0.002(0.00 \\
0)^{*}\end{array}$ & $\begin{array}{c}0.002(0.000 \\
)^{*}\end{array}$ & $0.002(0.000)^{*}$ \\
\hline $\begin{array}{l}\text { Between-child } \\
\text { intercept slope } \\
\text { variance } \\
\text { covariance } \\
\left(\text { age }^{2}\right)\end{array}$ & $\begin{array}{c}- \\
0.025(0.00 \\
2)^{* * *}\end{array}$ & $\begin{array}{c}- \\
0.025(0.00 \\
2)^{* * *}\end{array}$ & $-0.001(0.001)$ & $\begin{array}{c}- \\
0.001(0.001 \\
)\end{array}$ & $\begin{array}{c}- \\
0.053(0.003) \\
* * *\end{array}$ & $\begin{array}{c}- \\
0.053(0.00 \\
3)^{* * *}\end{array}$ & $\begin{array}{c}- \\
0.017(0.001 \\
)^{* * *}\end{array}$ & $\begin{array}{c}- \\
0.017(0.001)^{*} \\
* *\end{array}$ \\
\hline $\begin{array}{l}\text { Between-child } \\
\text { slope (age) } \\
\text { slope (age }{ }^{2} \text { ) } \\
\text { variance } \\
\text { covariance }\end{array}$ & $\begin{array}{c}- \\
0.001(0.00 \\
0)\end{array}$ & $\begin{array}{c}- \\
0.001(0.00 \\
0)\end{array}$ & $\begin{array}{c}- \\
0.008(0.000)^{* *} \\
*\end{array}$ & $\begin{array}{c}- \\
0.008(0.000 \\
)^{* * *}\end{array}$ & $\begin{array}{c}- \\
0.009(0.000) \\
* * *\end{array}$ & $\begin{array}{c}- \\
0.009(0.00 \\
0)^{* * *}\end{array}$ & $\begin{array}{c}- \\
0.005(0.000 \\
)^{* * *}\end{array}$ & $\begin{array}{c}- \\
0.005(0.000)^{*} \\
* *\end{array}$ \\
\hline
\end{tabular}




\begin{tabular}{|c|c|c|c|c|c|c|c|c|}
\hline $\begin{array}{l}\text { Between- } \\
\text { occasion } \\
\text { variance }\end{array}$ & $\begin{array}{c}1.183(0.01 \\
7)^{* * *}\end{array}$ & $\begin{array}{c}1.183(0.01 \\
7)^{* * *}\end{array}$ & $\begin{array}{c}0.982(0.014)^{* *} \\
*\end{array}$ & $\begin{array}{c}0.982(0.014 \\
)^{* * *}\end{array}$ & $\begin{array}{c}1.744(0.025) \\
* * *\end{array}$ & $\begin{array}{c}1.743(0.02 \\
5)^{* * *}\end{array}$ & $\begin{array}{c}0.957(0.014 \\
)^{* * *}\end{array}$ & $\begin{array}{c}0.957(0.014)^{*} \\
* *\end{array}$ \\
\hline Log Likelihood & $\begin{array}{c}151538.14 \\
6\end{array}$ & $\begin{array}{c}151535.64 \\
2\end{array}$ & 145384.276 & 145416.004 & 172130.682 & $\begin{array}{c}172134.08 \\
0\end{array}$ & 144139.021 & 144132.487 \\
\hline
\end{tabular}

Note. Disadv = disadvantaged; adv = advantaged; maternal depression = mother is at risk of depression; SWM $=$ spatial working memory; ${ }^{*} p<.05 ;{ }^{* *} p<$ $.01{ }^{* * *} p<.001$. 


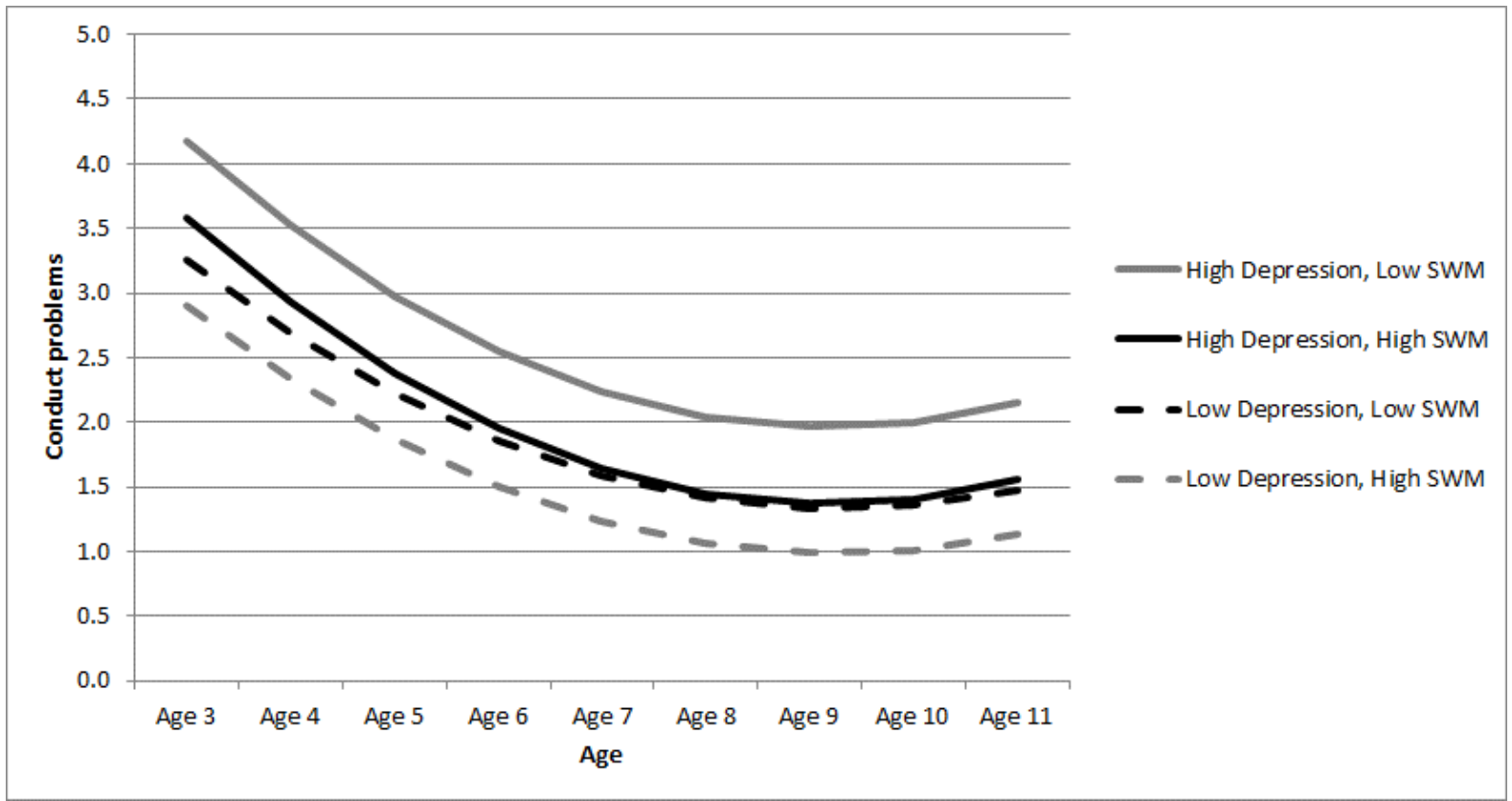

Figure 1. Predicted child conduct problem trajectories by high/low maternal depression and high/low spatial working memory (SWM) (Model 6)

Note: Predictions are plotted for the reference group for each categorical variable, except for ethnicity and family structure, and at the mean of each continuous variable. High maternal depression and high spatial working memory correspond to scores at the $90^{\text {th }}$ and $10^{\text {th }}$ percentiles, respectively. Low maternal depression and low spatial working memory correspond to scores at the $10^{\text {th }}$ and $90^{\text {th }}$ percentiles, respectively. 


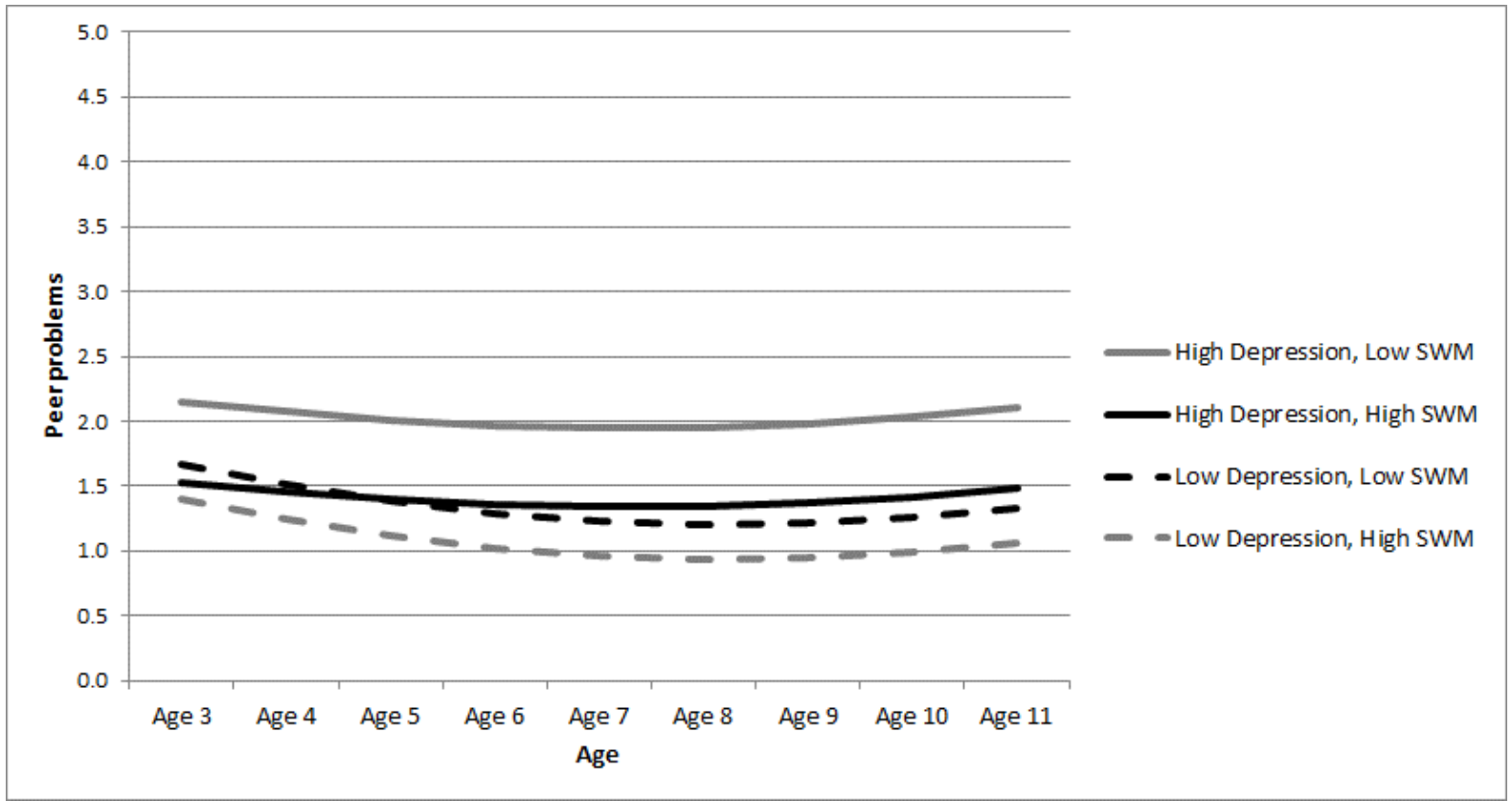

Figure 2. Predicted child peer problem trajectories by high/low maternal depression and high/low spatial working memory (SWM) (Model 6)

Note: See note to Figure 1. 


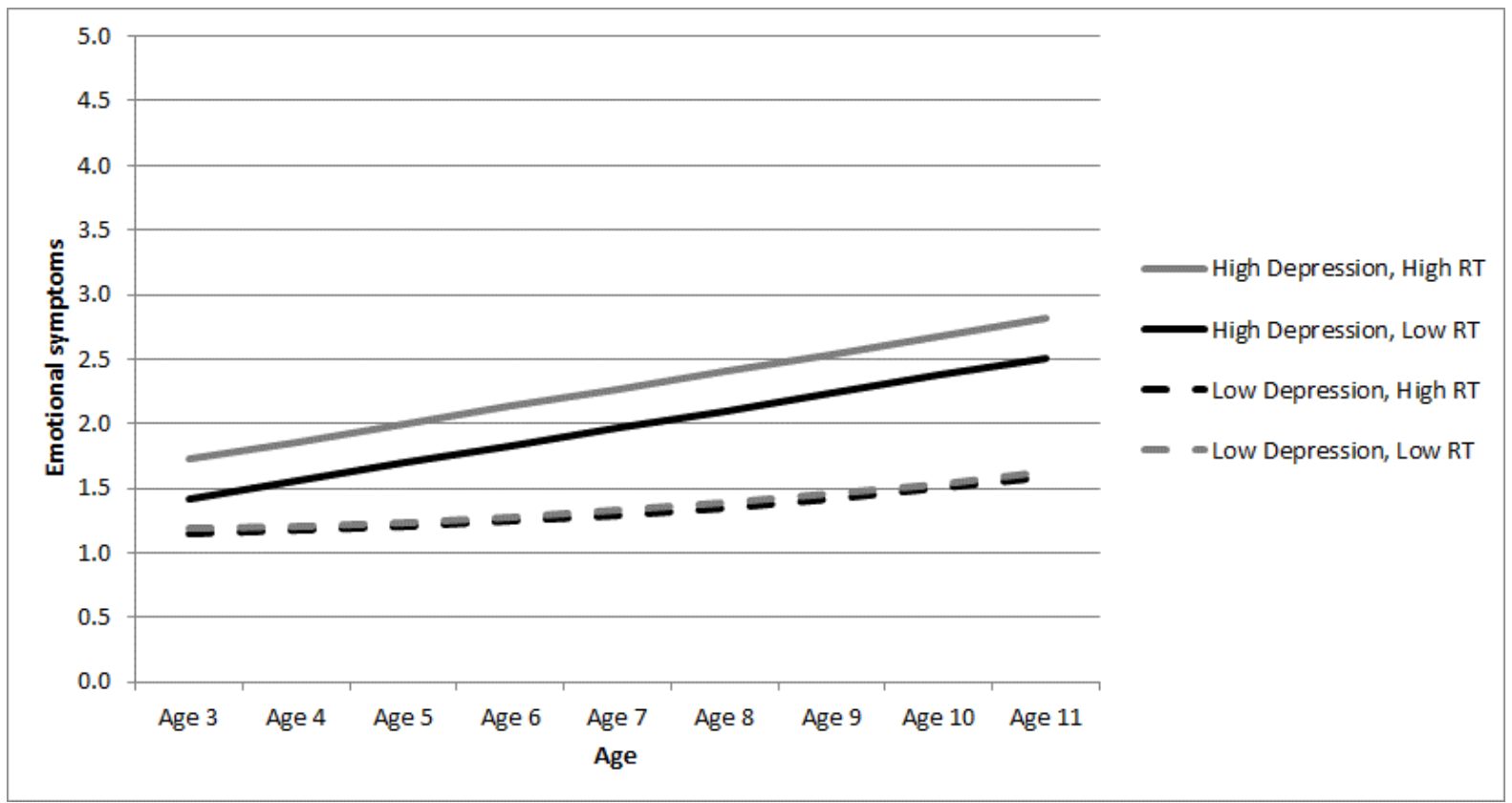

Figure 3. Predicted child emotional symptom trajectories by high/low maternal depression and high/low risk taking (RT) (Model 6)

Note: Predictions are plotted for the reference group for each categorical variable, except for ethnicity and family structure, and at the mean of each continuous variable. High maternal depression and high risk taking correspond to scores at the $90^{\text {th }}$ percentile. Low maternal depression and low risk taking correspond to scores at the $10^{\text {th }}$ percentile. 


\section{References}

Arnsten AF (2009). Stress signalling pathways that impair prefrontal cortex structure and function. Nature Reviews Neuroscience 10, 410-422.

Baune BT, Fuhr M, Air T, Hering C (2014). Neuropsychological functioning in adolescents and young adults with major depressive disorder: A review. Psychiatry Research 218, 261-271.

Beardslee WR, Gladstone, TR, O'Connor EE (2011). Transmission and prevention of mood disorders among children of affectively ill parents: A review. Journal of the American Academy of Child and Adolescent Psychiatry 50, 1098-1109.

Bechara A, Damasio H, Tranel D, Anderson SW (1998). Dissociation of working memory from decision making within the human prefrontal cortex. The Journal of Neuroscience 18, 428-437.

Brewin CR, Smart L (2005). Working memory capacity and suppression of intrusive thoughts. Journal of Behaviour Therapy and Experimental Psychiatry 36, 61-68.

Castellanos FX, Tannock R (2002). Neuroscience of attention-deficit/hyper-activity disorder: The search for endophenotypes. Nature Reviews Neuroscience 3, 617-628.

Cohen G, Conway MA (2008). Memory in the real world. 3rd ed. Psychology Press: Hove, England.

Crone E, van der Molen M (2004) Developmental changes in real-life decision-making: Performance on a gambling task previously shown to depend on the ventromedial prefrontal cortex.

Developmental Neuropsychology 25, 251-279.

Ernst M, Grant SJ, London ED, Contoreggi CS, Kimes AS, Spurgeon L (2003). Decision making in adolescents with behavior disorders and adults with substance abuse. American Journal of Psychiatry 160, 33-40.

Fellows LK, Farah MJ (2005). Different underlying impairments in decision-making following ventromedial and dorsolateral frontal lobe damage in humans. Cerebral Cortex 15, 58-63.

Flouri E, loakeimidi S, Midouhas E, Ploubidis GB (under review). Trajectories of maternal depressive symptoms and child decision making.

Galván A, McGlennen KM (2012). Daily stress increases risky decision-making in adolescents: A preliminary study. Developmental Psychobiology 54, 433-440.

Gathercole SE, Pickering SJ, Ambridge B, Wearing H (2004). The structure of working memory from 4 to 15 years of age. Developmental Psychology 40, 177-190.

Goodman R (1997). The strengths and difficulties questionnaire: A research note. Journal of Child Psychology and Psychiatry 38, 581-586.

Goodman SH, Rouse MH, Connell AM, Broth MR, Hall CM, Heyward D (2011). Maternal depression and child psychopathology: A meta-analytic review. Clinical Child and Family Psychology Review 14, 1-27. 
Gorka SM, Liu H, Klein D, Daughters SB, Shankman SA (2015). Is risk-taking propensity a familial vulnerability factor for alcohol use? An examination in two independent samples. Journal of Psychiatric Research 68, 54-60.

Grenard JL, Ames SL, Wiers RW, Thush C, Sussman S, Stacy AW (2008). Working memory capacity moderates the predictive effects of drug-related associations on substance use. Psychology of Addictive Behaviors 22, 426-432.

Hofmann W, Schmeichel BJ. Baddeley AD (2012). Executive functions and self-regulation. Trends in Cognitive Sciences 16, 174-180.

Joormann J, Levens SM, Gotlib IH (2011). Sticky thoughts depression and rumination are associated with difficulties manipulating emotional material in working memory. Psychological Science 22, 979983.

Kessler RC, Barker PR. Colpe L, Epstein JF, Gfroerer JC, Hiripi E, Howes MJ, Normand SL, Manderscheid RW, Walters EE, Zaslavsky AM (2003). Screening for serious mental illness in the general population. Archives of General Psychiatry 60, 184-189.

Kiernan KE, Mensah FK (2009). Poverty, maternal depression, family status and children's cognitive and behavioural development in early childhood: A longitudinal study. Journal of Social Policy 38, 569-588.

Klimes-Dougan B, Ronsaville D, Wiggs EA, Martinez PE (2006). Neuropsychological functioning in adolescent children of mothers with a history of bipolar or major depressive disorders. Biological Psychiatry 60, 957-965.

Klingberg $\mathbf{T}$, Forssberg $\mathbf{H}$, Westerberg $\mathbf{H}$ (2002). Training of working memory in children with ADHD. Journal of Clinical and Experimental Neuropsychology 24, 781-791.

Lewandowski RE, Verdeli H, Wickramaratne P, Warner V, Mancini A, Weissman M (2014).

Predictors of positive outcomes in offspring of depressed parents and non-depressed parents across 20 years. Journal of Child and Family Studies 23, 800-811.

Malmberg LE, Flouri E (2011). The comparison and interdependence of maternal and paternal influences on young children's behavior and resilience. Journal of Clinical Child and Adolescent Psychology 40, 434-444.

Manes F, Sahakian B, Clark L, Rogers R, Antoun N, Aitken M, Robbins T (2002). Decision-making processes following damage to the prefrontal cortex. Brain 125, 624-639.

Mannie ZN, Williams C, Browning M, Cowen PJ (2015). Decision making in young people at familial risk of depression. Psychological Medicine 45, 375-380.

Melby-Lervåg M, Hulme C. (2013). Is working memory training effective? A meta-analytic review. Developmental Psychology 49, 270-291.

McQuade JD, Murray-Close D, Shoulberg EK, Hoza B (2013). Working memory and social functioning in children. Journal of Experimental Child Psychology 115, 422-435. 
Morgan JK, Shaw DS, Forbes EE (2014). Maternal depression and warmth during childhood predict age 20 neural response to reward. Journal of the American Academy of Child and Adolescent Psychiatry 53, 108-117.

Pargas RCM, Brennan PA, Hammen C, Le Brocque R (2010). Resilience to maternal depression in young adulthood. Developmental Psychology 46, 805-814.

Pickering SJ (2001). The development of visuo-spatial working memory. Memory 9, 423-432.

Rawal A, Collishaw S, Thapar A, Rice, F. (2013). The risks of playing it safe: A prospective longitudinal study of response to reward in the adolescent offspring of depressed parents. Psychological Medicine 43, 27-38.

Riglin L, Collishaw S, Shelton KH, McManus IC, Ng-Knight T, Sellers R, Thapar AK, Fredrickson N, Rice $\mathbf{F}$ (2015). Higher cognitive ability buffers stress-related depressive symptoms in adolescent girls. Development and Psychopathology 24, 1-13.

Robbins TW, James M, Owen AM, Sahakian BJ, McInnes L, Rabbitt P (1994). Cambridge Neuropsychological Test Auto-mated Battery (CANTAB): A factor analytic study of a large sample of normal elderly volunteers. Dementia 5, 266-281.

Rogers RD, Owen AM, Middleton HC, Williams EJ, Pickard JD, Sahakian BJ, Robbins TW (1999). Choosing between small, likely rewards and large, unlikely rewards activates inferior and orbital prefrontal cortex. The Journal of Neuroscience 15, 9029-9038.

Rutter M (2012). Resilience as a dynamic concept. Development and Psychopathology 24, 335-344.

Smith AR, Chein J, Steinberg L (2013). Impact of socio-emotional context, brain development, and pubertal maturation on adolescent risk-taking. Hormones and Behavior 64, 323-332.

Smith DG, Xiao, L, Bechara A (2012). Decision making in children and adolescents: Impaired lowa Gambling Task performance in early adolescence. Developmental Psychology 48, 1180-1187.

Snijders T, Bosker R (1999). Multilevel analysis: An introduction to basic and applied multilevel analysis. Sage: Newbury Park, CA.

Steinberg L (2005). Cognitive and affective development in adolescence. Trends in Cognitive Sciences 9, 69-74.

Toplak ME, Sorge GB, Benoit A, West RF, Stanovich KE (2010). Decision-making and cognitive abilities: A review of associations between lowa Gambling Task performance, executive functions, and intelligence. Clinical Psychology Review 30, 562-581. 